\title{
Predictors and Prognostic Significance of Persistent Fluid Overload: a Longitudinal Study in Chinese Peritoneal Dialysis Patients
}

Jack Kit-Chung Ng ( $\sim$ kitchungng@hotmail.com )

Chinese University of Hong Kong https://orcid.org/0000-0002-9549-9611

Bonnie Ching-Ha Kwan

The Chinese University of Hong Kong

Gordon Chun-Kau Chan

The Chinese University of Hong Kong

Kai-Ming Chow

The Chinese University of Hong Kong

Wing-Fai Pang

The Chinese University of Hong Kong

Phyllis Mei-Shan Cheng

The Chinese University of Hong Kong

Chi-Bon Leung

The Chinese University of Hong Kong

Philip Kam-Tao Li

The Chinese University of Hong Kong

Cheuk-Chun Szeto

The Chinese University of Hong Kong

\section{Research Article}

Keywords: bioimpedance, fluid overload, mortality, peritoneal dialysis

Posted Date: February 19th, 2021

DOI: https://doi.org/10.21203/rs.3.rs-236782/v1

License: (c) (1) This work is licensed under a Creative Commons Attribution 4.0 International License. Read Full License 


\section{Abstract}

Background: Cross-sectional studies showed that fluid overload (FO) measured by bioimpedance spectroscopy (BIS) predicted adverse outcomes in patients on peritoneal dialysis (PD). We describe the longitudinal change in volume status in Chinese PD patients, and determine its relation with clinical outcomes.

Methods: We performed a single-center, retrospective analysis of all PD patients who underwent repeated BIS from 2010 to 2015. FO was defined by relative hydration index (RHI; volume of overhydration adjusted by extracellular water $>7 \%$ ). Variability of volume status (VVS) was denoted by the standard deviation of all RHI. The association of time-averaged $\mathrm{RHI}$ and VVS on patient and technique survival was explored by a competing risk model.

Results: A total of 269 patients were followed for a median of 47.1 months. Multivariate mixed linear regression revealed that $\mathrm{RHI}$ was significantly associated with time-varying systolic blood pressure, and inversely with time-varying albumin level, lean tissue index and fat tissue index $(P<0.0001$ for all). Patients without FO at baseline, as compared with those who had FO, showed significantly more fluid accumulation with time (adjusted between-group mean difference in $\mathrm{RHI}$ : $3.2 \%$ per year, $95 \%$ confidence interval $[\mathrm{Cl}] 1.5$ to $4.9 \%, \mathrm{P}=0.0002$ ). Time-averaged $\mathrm{RHI}$ independently predicted patient survival (subdistribution hazard ratio [SHR] 1.05, 95\% Cl 1.03-1.08, P <0.0001) and technique survival (SHR 1.04, $95 \% \mathrm{Cl} 1.01-1.06, \mathrm{P}=0.001)$, whereas VVS did not.

Conclusions: Persistent FO was a strong predictor of patient and technique failure. Repeated bioimpedance measurements for the monitoring of volume status provided additional prognostic information in PD patients.

\section{Introduction}

Maintaining euvolemia is one of the most important treatment goals for patients on peritoneal dialysis (PD), who have exceedingly high burden of cardiovascular diseases (CVD) [1, 2]. However, traditional clinical assessments are often unreliable and subjective, especially in detecting occult fluid overload (FO). In contrast, bioimpedance study enables quantitative measurement of body composition which are noninvasive and highly reproducible [3, 4]. Published evidences suggested that FO defined by bioimpedance methods predicted patient survival, technique survival and CVD in PD patients [5-9]. However, some of these studies only assessed hydration status at baseline [5-7], while others with repeated bioimpedance measurement were limited by small sample size or relatively short duration of follow up $[8,9]$.

On the other hand, the relationship between variation of volume status and clinical outcomes was seldom studied. A retrospective study showed that higher standard deviation (SD) of extracellular water/intracellular water (E/I ratio), which indicated more fluctuation in hydration status, was associated 
with mortality and technique failure [10]. However, the association became insignificant after adjustment of nutrition and inflammation. Recently, the Initiative for Patient Outcomes in Dialysis-Peritoneal Dialysis (IPOD-PD) study reported that the volume status of incident PD patients tended to stabilize over time; and baseline clinical parameters and PD prescription did not predict change in volume status over first 6 months [11]. Repeated measurements of volume status over a longer period of follow up may provide additional insight on the variability of volume status and potential modifiable factors on the course of hydration status.

In the present study, we aimed at describing the longitudinal changes in volume status of Chinese PD patients, and to explore predictive factors of volume status. Second, we evaluated the prognostic value of repeated bioimpedance measurements compared with single baseline measurement. Third, we examined the association between variability in volume status and clinical outcomes.

\section{Patients And Methods}

\section{Study design}

This study was approved by the Joint Chinese University Hong Kong-New Territories East Cluster Clinical Research Ethics Committee. All studies procedures are in compliance with the Declaration of Helsinki. We retrospectively reviewed all PD patients who were followed up in a tertiary hospital from January 2010 to December 2015. Patients with a minimum of two body composition measurements were included into the study. Both incident ( $\leq 4$ weeks after initiation of PD) and prevalent ( $>4$ weeks after PD) patients were eligible. Patients who had history of metallic prosthesis or pacemaker implantation were contraindicated for bioimpedance study and thus were excluded.

\section{Data collection}

Baseline demographics and PD prescriptions were retrieved by reviewing medical records of patients. Charlson's Comorbidity Index (CCl) was calculated to reflect the burden of comorbidities [12]. Systolic blood pressure (SBP), diastolic blood pressure (DBP) and body weight (BW) were measured during baseline and at subsequent bioimpedance studies, which were performed approximately every 12 months during clinic follow up. Laboratory data within two months of bioimpedance study were recorded for analysis. Patients with baseline urine output $<200 \mathrm{ml}$ were considered as anuric.

\section{Bioimpedance spectroscopy measurement}


We determined the volume status of PD patients by using a validated multi-frequency bioimpedance spectroscopy device (Body Composition Monitor [BCM], Fresenius Medical Care, Germany) [13]. In essence, BCM measures impedance by passing electric current with 50 different frequencies via two electrodes attached on the patients in a spine position. Based on a three-compartment model which assumes normally hydrated adipose and lean tissues, excessive fluid can be estimated and expressed in absolute liters of volume of overhydration $(\mathrm{OH})$ [14]. We also calculated the relative percentage of excessive fluid by dividing $\mathrm{OH}$ by extracellular water (ECW), which was known as relative hydration index (RHI) [15].

Patients were considered to have no, mild, moderate and severe FO if their RHI was $£ 7 \%,>7.0$ to $15.0 \%$, $>15.0$ to $25.0 \%$ and $>25.0 \%$, respectively $[15,16]$. Volume status of individual patient was represented by baseline RHI and time-averaged RHI (defined as the weighted mean of all RHI of each patient, with weights representing the time elapsed since the previous measurement). On the other hand, variability of volume status (VVS) was denoted by standard deviation (SD) and of all RHI.

In addition to volume status, nutritional parameters including fat tissue index (FTI) and lean tissue index (LTI) were automatically computed by BCM. Clinicians were allowed to adjust PD prescriptions at their discretion based on BCM data.

\section{Follow up and outcomes}

All patients were followed until $31^{\text {st }}$ July 2017. Outcomes included patient survival and technique survival, which was defined as a composite of death or transfer to long term hemodialysis (HD).

\section{Statistical analyses}

Continuous data are presented as mean \pm SD or median (inter-quartile range [IQR]). Baseline characteristics of patients with different degree of FO were compared by one way analysis of variance (ANOVA) or Chi-square test where appropriate. Then we constructed a linear mixed model to present the change of RHI from baseline to the fourth year of follow up (BCM measurements in Year 5 were excluded due to limited number of data). Subjects were included as random intercept, while time of BCM measurements (number of years after baseline assessment) were included as fixed effect. Baseline FO $(\mathrm{RHI} \leq 7 \%$ vs. $>7 \%)$, residual urine output (anuric vs. non-anuric), baseline diabetes, baseline albumin level 
(albumin level $\leq 30 \mathrm{vs}$. $>30 \mathrm{~g} / \mathrm{L}$ ), gender, and the interaction of these factors with time were included as fixed effects. Parameter(s) which achieved $P \leq 0.1$ in univariate analysis were included as time-varying co-variate(s). An autoregressive covariance was assumed.

Kaplan-Meier method with log-rank test was used to compare survival curves between patients in different categories of FO defined by time-averaged RHI. The association between $\mathrm{RHI}$ and patient and technique survival was then examined by Fine and Gray competing risk model [17], with adjustment for age, gender, $\mathrm{CCl}$, body mass index, serum albumin, weekly Kt/V and residual urine output. Change to HD and transplantation were considered as competing risks of patient survival; and transplantation was considered as competing risk of technique survival. SD of OH/ECW, the surrogate of VVS, were natural log-transformed due to skewed distribution. Baseline RHI together with potential confounders measured at baseline (as stated above), and time-averaged $\mathrm{RHI}$ with the same time-averaged parameters were analyzed in two separate multivariate competing risk model. VVS was subsequently forced into the timeaveraged model. The difference in predictive power of each model was compared by Wald's test. In a sensitivity analysis, we repeated our survival analyses with patients with $\geq 3 \mathrm{RHI}$ measurements.

All statistical analyses were performed by SPSS for Windows software (version 24.0. IBM Corporation, Armonk, NY) and Stata version 15 (StataCorp LP, College Station, Tx). A P value of less than 0.05 was considered significant. All probabilities were two-tailed.

\section{Results}

Bioimpedance studies were performed in 337 patients during the study period, in which 272 patients had at least two repeated measurements. 269 patients with complete body composition data were included in the final cohort. At baseline, 158 (58.6\%) was male and the mean age was $59.7 \pm 11.5$ years; $13.4 \%$ of them were on automated peritoneal dialysis (APD) (Table 1). The overall prevalence of diabetes was $54.6 \%$. First BCM study showed that $58(21.6 \%)$ patients had mild FO, while $164(61.0 \%)$ had moderate to severe FO . Patients with FO were older yet with a shorter dialysis vintage. They had higher SBP, higher prevalence of diabetes and heavier burden of comorbidities. Besides, FO was accompanied by a significantly lower albumin level, and a trend towards anemia. Nevertheless, there was no significant difference between weekly Kt/V, residual glomerular filtration rate (GFR), or urine output (Table 1 and S1).

\section{Change in volume status over time}

A total of 699 bioimpedance studies were performed during the study period. The number of bioimpedance studies that a patient underwent ranged from 2 to 5 . The median number of 
measurements were 2 (IQR 2-3); 40.5\% of patients were studied 3 times or more. The median interval between consecutive BCM measurements was 12.1 (IQR 10.5-13.3) months.

At Year 0, the median RHI was 18.3\% (IQR 10.5-26.1\%). It decreased to 16.2\% (IQR 8.1-24.6\%) after the first year, which was followed by a numerical increase from second to fifth year (Figure 1 and Table S2). The proportion of patients with FO was $82.5 \%, 79.1 \%$ and $86.2 \%$ in Year 0,1 and 2, respectively (Table S2). Unadjusted mixed linear model, however, did not reveal an overall change in RHI with time $(P=0.21)$. Mean time-averaged RHI and median VVS was $17.6 \pm 10.2 \%$ and 6.3\% (IQR 3.2-9.1\%), respectively.

In subsequent multivariate mixed linear regression analysis, we found that RHI was significantly associated with baseline diabetes, time-varying SBP, and inversely with time-varying albumin level, weekly $\mathrm{Kt} / \mathrm{V}, \mathrm{LTI}$ and $\mathrm{FTI}$ (Table 2). In contrast, baseline peritoneal transport status $(\mathrm{P}=0.89)$ and residual urine output $(P=0.45)$ were not associated with change in volume status.

Among the pre-specified subgroups, we found that baseline hydration status ( $\mathrm{RHI}>7 \%$ vs. $\leq 7 \%, \mathrm{P}=0.001$ ) and residual urine output ( $<200 \mathrm{ml} /$ day vs. $\geq 200 \mathrm{ml} /$ day, $\mathrm{P}=0.04$ ) significantly modified the relationship between volume status and year of assessment (Table 3). Patients who had FO (RHI >7\%) at the beginning of study had significantly higher RHI compared with the others, but the adjusted difference between two groups diminished with time (Figure 2a). The adjusted mean difference in change in RHI between euvolemic versus FO patients was $3.2 \%$ per year ( $95 \% \mathrm{Cl} 1.5$ to $4.9 \%, \mathrm{P}=0.0002$ ) (Table 3 ). In addition, the adjusted difference in $\mathrm{RHI}$ between anuric versus non-anruic group was $1.4 \%$ per year (95\% $\mathrm{Cl}-0.9$ to $3.7 \%$ ) (Figure 2B), which may suggest progressive fluid accumulation in anuric patients, although the difference did not reach statistical significance. On the other hand, there was no interaction between time and other covariates (age, gender, diabetes and baseline albumin level).

\section{Patient and technique survival}

All patients were followed for a median of 47.1 (IQR 32.0-60.3) months. During this period, 121 patients died. Their causes of death were non-peritonitis infections (47 cases), cardiovascular diseases (27 cases), cerebrovascular diseases ( 16 cases), peritonitis ( 9 cases) and malignancy ( 7 cases). In addition, 25 patients were transferred to long term hemodialysis, 16 received kidney transplant, and 4 were transferred to another center. 
At 60 months, patient survival was $77.2 \%, 62.5 \%, 42.1 \%$ and $31.9 \%$ (log-rank test, $\mathrm{P}<0.0001$ ) in patients with nil, mild, moderate and severe FO (by time-averaged $\mathrm{RHI}$ ), while technique survival was $66.2 \%, 59.3 \%$, 38.3 and $25.6 \%(P<0.0001)$ accordingly (Figure 3$)$. Compared with patient with persistent euvolemia (time-averaged $\mathrm{RHI} \leq 7 \%$ ), patients with persistent moderate or severe FO had significant increased risk of death (Subdistribution Hazard Ratio [SHR] 2.66, 95\% Cl 1.12 to $6.31, \mathrm{P}=0.03$; and SHR 4.19, $95 \% \mathrm{Cl} 1.69$ to $10.41, P=0.002$, respectively) in multivariate competing risk analysis, respectively. The mortality risk for patients with persistent FO was consistently higher than those with baseline FO with the same degree of FO. (baseline moderate FO: SHR 2.11, $95 \% \mathrm{Cl} 0.91$ to 4.87, P =0.09; baseline severe FO: SHR 2.52, $95 \%$ Cl 1.07 to $5.91, \mathrm{P}=0.03$ ) (Table S3).

To evaluate the prognostic value of VVS and repeated BCM measurement, we created three competing risk models which were adjusted for the same confounders as Table S3 (Table 4). In essence, both baseline RHI and time-averaged RHI were independent predictor of patient and technique surviva, whereas VVS were not. Notably, time-averaged RHI provided additional prognostic value compared with baseline RHI in both patient (Model 2 vs. Model 1, $\mathrm{P}=0.0001$ ) and technique survival (Model 2 vs. Model $1, P=0.002)$ (Table 4). In a sensitivity analysis which only included $\geq 3$ BCM measurements $(n=106), V V S$ was not associated with mortality $(P=0.22)$ nor technique failure $(P=0.69)$.

\section{Discussion}

In this longitudinal cohort of Chinese PD patients, FO measured by BCM was present in a substantial proportion of patients at baseline which persisted over time. Hypervolemia was strongly associated with diabetes, malnutrion, inadequate dialysis, and diminshed lean and fat body mass. Moreover, persistent FO, instead of VVS, independently predicted patient and techqniue survival. Compared with FO measured at a single time-point, persistent FO was assoicated with a significanlty greater risk of mortality and techiqnue failure.

Previous studies suggested that volume status of PD patients hardly changed after 12 months of follow up [8]. In our study, RHI decreased from $18.3 \%$ to $16.2 \%$ after the first year; and similar decline was also observed in the IPOD-PD study (baseline RHI: 9.7\%; Year 1: RHI 6.6\%) [11]. This discrepancy could be attributed to the difference in baseline volume status: the average $\mathrm{RHI}$ in the cohort by Kim et al $(7.6 \%$ [IQR -0.1-15.6\%]) [8] was remarkably lower than that in our study (18.3\% [IQR 10.5-26.1\%]) and IPOD-PD study $(9.7 \pm 11.1 \%)[11]$. Therefore it may not be surprising that initial improvement of volume status was largely observed in the latter two studies, in which the BCM findings may prompt the clinicians for optimization of fluid status. However, while volume status tended to stabilize with roughly $50 \%$ of patients rendered euvolemic in IPOD-PD study, our results indicated that over $70 \%$ of PD patients remained hypervolemic in subsequent follow up (Table S2). Instead of a 'regression-to-mean' phenomenon (patients with hypo- and hypervolemia both progressed to euvolemia) [11], our study may 
suggest a different trajectory of volume status which was significantly modified by baseline volume status (Figure 2A). Baseline euvolemic ( $\mathrm{RHI} \leq 7 \%$ ) PD patients experienced progressive fluid accumulation (mean annual change in $\mathrm{RHI}: 2.6 \%$ [95\% $\mathrm{Cl} 1.1$ to $4.2 \%]$ ), while those with $\mathrm{FO}$ in the beginning showed little change in hydration status (mean annual change: $-0.6 \%$ [ $95 \% \mathrm{Cl}-1.4$ to $0.3 \%$; adjusted mean difference between groups: 3.2\% [95\% 1.5 to $4.9 \%]$ ), after adjusting for age, gender, nutritional status and dialysis adequacy. This reiterated that regular monitoring of volume status, as recommended by International Society for Peritoneal Dialysis [18], was important and this may also need to be considered in patients who were initially euvolemic.

Similar to the findings of previous cross-sectional studies [7, 15, 19], our study (Table 2) showed that diabetes $(P<0.0001)$, hypoalbuminemia $(P<0.0001)$, lower weekly $\mathrm{Kt} / \mathrm{V}(P=0.006)$ were independent predictors of hypervolemia. Of note was that our longitudinal study with repeated measurements over a long duration of follow up provided more robust evidence to affirm their associations. On the other hand, residual urine volume and baseline peritoneal transporter status were not associated with volume status. This suggested that dietary compliance and appropriate adaption of dwell length to transporter status may play a greater role in maintaining normohydration. Interestingly, we found that time-varying FTI ( $P$ $<0.0001)$ and LTI $(P<0.0001)$ were inversely associated with volume status. This combination of low fat and lean body mass, and hypoalbuminemia constituted the phenotype of protein-energy wasting, which was previously shown to correlate with overhydration [19]. Systemic inflammation, which is prevalent among dialysis patients, may result in unnoticed reduction in FTI or LTI and inaccurate estimation of dry weight [20], culminating in fluid retention. Reciprocally, FO may indirectly cause muscle wasting by aggravating inflammation via increased bacterial translocation through bowel wall [21, 22].

Previous studies suggested that visit-to-visit blood pressure variability was associated with increase in mortality and cardiovascular events in HD patients [23, 24]. This variability was, at least partially, attributed by the drastic and non-physiological change in extracellular volume during HD, which was followed by interdialytic fluid accumulation. Likewise, aggressive fluid control in overhydrated PD patients might lead to rapid fluctuation of fluid status, which causes depletion in intravascular volume and organ hypoperfusion. It had been reported that PD patients with greater fluid variation had faster decline in GFR and urine output [25]. Another single-center Chinese study examined the association of SD of $E / I$ ratio (as the proxy of magnitude of changes in volume status over time) and clinical outcomes [10]. However, the prognostic value of E/I ratio was confounded by nutritional state and C-reactive protein [10]. The predictive power of $\mathrm{RHI}$ (in the present study) was known to be independent of nutrition and inflammation [5]. Nevertheless, we were still unable to demonstrate any significant association between VVS and patient or technique survival. One of the possible reasons may be that relative long interval between BCM masked the underlying variability. The fact that approximately half of patients only 
underwent BCM twice may also fail to unravel VVS. However, sensitivity analysis which included $\geq 3 \mathrm{BCM}$ measurements produced similar results.

In a multivariate competing risk model adjusted for age, gender, comorbidities, dialysis adequacy and nutrition (Table 4), every $1 \%$ increase in time-averaged $\mathrm{RHI}$ was significantly associated with $5 \%$ increase in mortality (SHR $1.05,95 \% \mathrm{Cl} 1.03$ to 1.08 ) and $4 \%$ increase in technique failure (SHR $1.04,95 \% \mathrm{Cl} 1.01$ to 1.06), respectively. When volume status was analyzed as a categorical variable, persistent moderate and persistent severe FO independently predicted a significant increase in mortality by 2.7 and 4.2 times, respectively. This risk was considerably higher compared to that associated with baseline FO within the same category (Table S3). This suggested that persistent FO was a stronger risk factor than FO based on cross-sectional measurement, which was a consistent finding from previous observational studies in both PD and HD patients $[8,26]$. This was particularly relevant because initial improvement in volume status was not uncommon (as in our cohort) when clinicians attempted to correct FO after knowing the first $\mathrm{BCM}$ data, and that may attenuate the predictive power of baseline FO. While cumulative exposure to FO was proved to increase the risk of HD conversion in short to medium term [8, 27], our study expanded the existing evidence that persistent FO remained a significant, and more importantly, modifiable predictor for technique failure after a median follow up of 47 months. Although analysis using time-averaged $\mathrm{RHI}$ as categorical variable seemed to fall short of significance (Table S3), the strong association when timeaveraged RHI was analyzed as continuous variable may suggest there was no reliable or universal cut-off to define FO in predicting technique failure.

Our study had a number of limitations. First, the inherent limitation of a retrospective observational study did not allow us to establish causality. Nevertheless, the longitudinal design with repeated, objective assessment by BCM provided more robust estimate between volume status and associated factors compared with cross-sectional studies. Second, survival bias may be present because only survivors would undergo repeated BCM measurements. However, given that CVD was one of the major causes of death and was closed related with FO, such bias was more likely to underestimate the risk. Third, data on ultrafiltration volume and salt intake were missing in many patients and thus not included for analyses. Nevertheless, ultrafiltration volume had not been shown to predict hypervolemia in both incident and prevalent patients $[7,15]$; and there was no simple surrogate for dietary sodium intake in clinical practice. Besides, we did not evaluate the impact of change in PD modality nor prescription because the use of APD and icodextrin were, to some extent, governed by availability. This was further complicated by the fact that interventions to ameliorate FO were often complex and multiple, such that the effect of single intervention was difficult to analyze even in the setting of randomized controlled trial [28]. Finally, we could not exclude type II error concerning the effect of VVS on clinical outcomes, given the limited number of BCM measurements. 
In conclusion, persistent FO was associated with increase in mortality and technique failure. Despite the additional prognostic value brought about by repeated bioimpedance measurements, there is unfortunately insufficient evidence that supports routine bioimpedance-guided fluid management would improve clinical outcomes $[29,30]$. Future studies are warranted to identify the subgroup that will benefit most for bioimpedance-guided fluid management.

\section{Declarations}

\section{Acknowledgement}

Nil.

\section{Funding}

This study was supported by the Chinese University of Hong Kong (CUHK) research accounts 6901031 and 7101215. The funders had no role in study design, data collection and analysis, decision to publish, or preparation of the manuscript.

\section{Conflicts of interest}

Prof. Philip Li received honorarium from Fibrogen. Other authors declared no conflict of interests.

\section{Ethics approval}

This study was approved by the Joint Chinese University Hong Kong-New Territories East Cluster Clinical Research Ethics Committee. All studies procedures are in compliance with the Declaration of Helsinki.

\section{Authors' contributions}

J.K.C.N., B.C.H.K. conceived the idea of this study. J.K.C.N. and C.C.S. devised the method of analysis. P.M.S.C performed all bioimpedance studies. B.C.H.K., G.C.K.C., W.F.P, K.M.C. collected data, and J.K.C.N and C.C.S. carried out the statistical analyses. J.K.C.N. prepared the manuscript. C.B.L., P.K.T.L. and C.C.S. supervised the whole project and provided mentorship. All authors provided intellectual input and endorsed to the final manuscript.

\section{Data availability statement}

The dataset generated and/or analyzed in this article will be shared upon reasonable request to the corresponding author.

\section{References}

1. Mehrotra R, Devuyst O, Davies SJ, Johnson DW (2016) The Current State of Peritoneal Dialysis. J Am Soc Nephrol. 27:3238-3252. 
2. Saran R, Robinson B, Abbott KC, et al (2019) US Renal Data System 2018 Annual Data Report: epidemiology of kidney disease in the United States. Am J Kidney Dis. 73(3)(suppl 1):Svii-Sxxii, S1S772.

3. Davies SJ, Davenport A (2014) The role of bioimpedance and biomarkers in helping to aid clinical decision-making of volume assessments in dialysis patients. Kidney Int. 86(3):489-96.

4. Ng JK, Li PK (2019) Fluid management and bioimpedance in peritoneal dialysis. Curr Opin Nephrol Hypertens. 28(1):58-64.

5. O'Lone EL, Visser A, Finney H, Fan SL (2014) Clinical significance of multi-frequency bioimpedance spectroscopy in peritoneal dialysis patients: independent predictor of patient survival. Nephrol Dial Transplant. 29:1430-7.

6. Guo Q, Lin J, Li J (2015)The Effect of Fluid Overload on Clinical Outcome in Southern Chinese Patients Undergoing Continuous Ambulatory Peritoneal Dialysis. Perit Dial Int. 35(7):691-702.

7. Ng JK, Kwan BC, Chow KM (2018) Asymptomatic Fluid Overload Predicts Survival and Cardiovascular Event in Incident Chinese Peritoneal Dialysis Patients. PLoS One.13(8): e0202203.

8. Kim JK, Song YR, Lee HS, Kim HJ, Kim SG (2018) Repeated Bioimpedance Measurements Predict Prognosis of Peritoneal Dialysis Patients. Am J Nephrol. 47(2):120-129.

9. Aguiar PV, Santos O, Teixeira L (2015) Overhydration prevalence in peritoneal dialysis - A 2 year longitudinal analysis. Nefrologia. 35(2):189-196.

10. Tian JP, Wang H, Du FH, Wang T (2016) The standard deviation of extracellular water/intracellular water is associated with all-cause mortality and technique failure in peritoneal dialysis patients. Int Urol Nephrol. 48(9):1547-1554.

11. Van Biesen W, Verger C, Heaf J, et al (2019) Evolution Over Time of Volume Status and PD-Related Practice Patterns in an Incident Peritoneal Dialysis Cohort. Clin J Am Soc Nephrol. 14(6):882-893.

12. Beddhu S, Zeidel ML, Saul M, et al (2002) The effects of comorbid conditions on the outcomes of patients undergoing peritoneal dialysis. Am J Med. 12:696-701.

13. Cooper BA, Astani A, Ryan M, et al (2000) Comparing different methods of assessing body composition in end-stage renal failure. Kidney Int. 58(1):408-16.

14. Chamney PW, Wabel P, Moissl UM, et al (2007) A whole-body model to distinguish excess fluid from the hydration of major body tissues. Am J Clin Nutr. 85:80-89.

15. Van Biesen W, Williams JD, Covic AC, et al (2011) Fluid status in peritoneal dialysis patients: the European Body Composition Monitoring (EuroBCM) study cohort. PLoS One. 6(2): e17148

16. Wizemann V, Wabel P, Chamney P, et al (2009) The mortality risk of overhydration in haemodialysis patients. Nephrol Dial Transplant. 24:1574-79.

17. Fine JP, Gray RJ (1999) A proportional hazards model for the subdistribution of a competing risk. J Am Stat Assoc. 94:496-509.

18. Wang AY, Brimble KS, Brunier G, et al (2015) ISPD Cardiovascular and Metabolic Guidelines in Adult Peritoneal Dialysis Patients Part I - Assessment and Management of Various Cardiovascular Risk 
Factors. Perit Dial Int. 35(4):379-87.

19. Guo Q, Yi C, Li J, et al (2013) Prevalence and risk factors of fluid overload in Southern Chinese continuous ambulatory peritoneal dialysis patients. PLoS One.8(1):e53294.

20. Dekker MJ, van der Sande FM, van den Berghe F, Leunissen KM, Kooman JP (2018) Fluid Overload and Inflammation Axis. Blood Purif. 45:159-165.

21. Wang XH, Mitch WE (2014). Mechanisms of muscle wasting in chronic kidney disease. Nat Rev Nephrol. 10(9):504-16.

22. Szeto CC, Mclntyre CW, Li PKT (2018). Circulating bacterial fragments as cardiovascular risk factors in CKD. J Am Soc Nephrol. 29(6): 1601-1608.

23. Shafi T, Sozio SM, Bandeen-Roche KJ, et (2014) Predialysis systolic BP variability and outcomes in hemodialysis patients. J Am Soc Nephrol. 25(4):799-809.

24. Chang TI, Flythe JE, Brunelli SM, et al (2014) Vist-to-visit systolic blood pressure variability and outcomes in hemodialysis. J Hum Hypertens. 28(1):18-24.

25. Tian N, Guo Q, Zhou Q, et al (2016) The Impact of Fluid Overload and Variation on Residual Renal Function in Peritoneal Dialysis Patient. PLoS One11(4):e0153115.

26. Zoccali C, Moissl U, Chazot C, et al (2017) Chronic Fluid Overload and Mortality in ESRD. J Am Soc Nephrol.28(8):2491-2497.

27. Vrtovsnik F, Verger C, Van Biesen W, et al. The impact of volume overload on technique failure in incident peritoneal dialysis patients. Clin Kidney J. https://doi.org/10.1093/ckj/sfz175.

28. Tan BK, Yu Z, Fang W, et al (2016) Longitudinal bioimpedance vector plots add little value to fluid management of peritoneal dialysis patients. Kidney Int. 89:487-497.

29. Oh KH, Baek SH, Joo KW, et al. (2018) Does Routine Bioimpedance-Guided Fluid Management Provide Additional Benefit to Non-Anuric Peritoneal Dialysis Patients? Results from COMPASS Clinical Trial. Perit Dial Int.38:131-138.

30. Tian N, Yang X, Guo Q, et al (2020). Bioimpedance Guided Fluid Management in Peritoneal Dialysis: A Randomized Controlled Trial. Clin J Am Soc Nephrol.15(5):685-694.

\section{Tables}

TABLE 1. Baseline demographics, biochemical data and dialysis characteristics in patients with no fluid overload $(\mathrm{OH} / \mathrm{ECW} \leq 7 \%)$, mild fluid overload (OH/ECW $>7.0$ to $15 \%)$, and moderate to severe fluid overload $(\mathrm{OH} / \mathrm{ECW}>15.0 \%)$. 


\begin{tabular}{|c|c|c|c|c|c|}
\hline & & fluid overlo & & & \\
\hline & all cases & no & mild & $\begin{array}{l}\text { moderate to } \\
\text { severe }\end{array}$ & P-value \\
\hline No. of patients & 269 & 47 & 58 & 164 & - \\
\hline Incident: prevalent & $51: 218$ & $4: 43$ & 9:49 & $38: 126$ & $0.058^{1}$ \\
\hline Duration of PD (months) & $\begin{array}{l}1.9(1.4 \\
\text { to } 3.6)\end{array}$ & $\begin{array}{l}3.7(1.7 \text { to } \\
25.3)\end{array}$ & $\begin{array}{l}2.6 \text { (1.6 to } \\
4.4)\end{array}$ & $\begin{array}{l}1.8(1.1 \text { to } \\
2.7)^{a, b}\end{array}$ & $\begin{array}{l}<0.0001 \\
2\end{array}$ \\
\hline Male (\%) & $58.7 \%$ & $51.1 \%$ & $58.6 \%$ & $61.0 \%$ & $0.48^{1}$ \\
\hline Age (year) & $\begin{array}{l}59.7 \pm \\
11.5\end{array}$ & $55.9 \pm 9.1$ & $\begin{array}{l}60.4 \pm \\
11.5\end{array}$ & $60.5 \pm 12.0^{c}$ & $0.04^{3}$ \\
\hline Blood pressure $(\mathrm{mmHg})$ & & & & & \\
\hline Systolic & $\begin{array}{l}135.3 \pm \\
21.0\end{array}$ & $\begin{array}{l}125.6 \pm \\
19.6\end{array}$ & $\begin{array}{l}133.8 \pm \\
19.2\end{array}$ & $\begin{array}{l}138.7 \pm 21.2 \\
b\end{array}$ & $0.001^{3}$ \\
\hline Diastolic & $\begin{array}{l}73.5 \pm \\
14.0\end{array}$ & $\begin{array}{l}75.2 \pm \\
12.8\end{array}$ & $\begin{array}{l}71.3 \pm \\
10.6\end{array}$ & $73.8 \pm 15.3$ & $0.34^{3}$ \\
\hline $\begin{array}{l}\text { Causes of renal failure, no. of } \\
\text { cases }(\%)\end{array}$ & & & & & $\begin{array}{l}<0.0001 \\
1\end{array}$ \\
\hline Diabetic nephropathy & $\begin{array}{l}123 \\
(45.7 \%)\end{array}$ & $4(8.5 \%)$ & $\begin{array}{l}22 \\
(37.9 \%)\end{array}$ & $97(59.1 \%)$ & \\
\hline Glomerulonephritis & $\begin{array}{l}65 \\
(24.2 \%)\end{array}$ & $23(48.9 \%)$ & $\begin{array}{l}16 \\
(27.6 \%)\end{array}$ & $26(15.9 \%)$ & \\
\hline Hypertensive nephrosclerosis & $\begin{array}{l}27 \\
(10.0 \%)\end{array}$ & $4(8.5 \%)$ & $\begin{array}{l}10 \\
(17.2 \%)\end{array}$ & $13(7.9 \%)$ & \\
\hline Polycystic kidney & $14(5.2 \%)$ & $4(8.5 \%)$ & $4(6.9 \%)$ & $6(3.7 \%)$ & \\
\hline Obstructive uropathy & $14(5.2 \%)$ & $4(8.5 \%)$ & $3(5.2 \%)$ & $7(4.3 \%)$ & \\
\hline Others / unknown & $26(9.6 \%)$ & $8(17.0 \%)$ & $3(5.1 \%)$ & $15(9.1 \%)$ & \\
\hline Comorbidities, no. of cases (\%) & & & & & \\
\hline Diabetes & $\begin{array}{l}147 \\
(54.6 \%)\end{array}$ & $9(19.1 \%)$ & $\begin{array}{l}25 \\
(43.1 \%)\end{array}$ & $113(68.9 \%)$ & $\begin{array}{l}<0.0001 \\
1\end{array}$ \\
\hline Ischemic heart disease & $\begin{array}{l}61 \\
(22.7 \%)\end{array}$ & $7(14.9 \%)$ & $\begin{array}{l}10 \\
(17.2 \%)\end{array}$ & $44(26.8 \%)$ & $0.12^{1}$ \\
\hline Cerebrovascular disease & $\begin{array}{l}60 \\
(22.3 \%)\end{array}$ & $6(12.8 \%)$ & $\begin{array}{l}15 \\
(25.9 \%)\end{array}$ & $39(23.8 \%)$ & $0.21^{1}$ \\
\hline Peripheral vascular disease & $17(6.3 \%)$ & $0(0 \%)$ & $2(3.4 \%)$ & $15(9.1 \%)$ & $0.045^{1}$ \\
\hline
\end{tabular}




\begin{tabular}{|c|c|c|c|c|c|}
\hline Charlson's Comorbidity Index & $5.5 \pm 2.3$ & $4.3 \pm 1.8$ & $\begin{array}{l}5.4 \pm 2.5 \\
d\end{array}$ & $5.8 \pm 2.2^{b}$ & $\begin{array}{l}<0.0001 \\
1\end{array}$ \\
\hline \multicolumn{6}{|l|}{ Laboratory parameters } \\
\hline Hemoglobin (g/dL) & $9.3 \pm 1.4$ & $9.6 \pm 1.4$ & $9.5 \pm 1.4$ & $9.1 \pm 1.4$ & $0.054^{3}$ \\
\hline Albumin $(g / L)$ & $34.7 \pm 4.5$ & $37.9 \pm 2.8$ & $\begin{array}{l}35.3 \pm 4.4 \\
\mathrm{e}\end{array}$ & $33.5 \pm 4.4^{\mathrm{a}, \mathrm{b}}$ & $\begin{array}{l}<0.0001 \\
3\end{array}$ \\
\hline \multicolumn{6}{|l|}{ Peritoneal transport } \\
\hline $\mathrm{D} / \mathrm{P}$ creatinine at 4 hour & $\begin{array}{l}0.66 \pm \\
0.14\end{array}$ & $\begin{array}{l}0.58 \pm \\
0.12\end{array}$ & $\begin{array}{l}0.68 \pm \\
0.12 \mathrm{e}\end{array}$ & $0.67 \pm 0.14^{b}$ & $\begin{array}{l}<0.0001 \\
3\end{array}$ \\
\hline Low transporter $(<0.5)$ & $\begin{array}{l}33 \\
(12.5 \%)\end{array}$ & $12(26.1 \%)$ & $3(5.2 \%)$ & $18(11.4 \%)$ & \multirow[t]{4}{*}{$0.002^{1}$} \\
\hline $\begin{array}{l}\text { Low-average transporter }(0.5 \text { - } \\
0.65)\end{array}$ & $\begin{array}{l}92 \\
(33.8 \%)\end{array}$ & $21(45.7 \%)$ & $\begin{array}{l}22 \\
(37.9 \%)\end{array}$ & $47(29.7 \%)$ & \\
\hline $\begin{array}{l}\text { High-average transporter (0.66- } \\
0.81)\end{array}$ & $\begin{array}{l}100 \\
(36.8 \%)\end{array}$ & $12(26.1 \%)$ & $\begin{array}{l}12 \\
(39.7 \%)\end{array}$ & $65(41.1 \%)$ & \\
\hline High transporter (>0.81) & $\begin{array}{l}40 \\
(14.7 \%)\end{array}$ & $1(2.2 \%)$ & $\begin{array}{l}10 \\
(17.2 \%)\end{array}$ & $28(17.7 \%)$ & \\
\hline \multicolumn{6}{|l|}{ Dialysis characteristics } \\
\hline $\begin{array}{l}\text { Use of icodextrin at baseline, } \\
\text { no. of cases (\%) }\end{array}$ & $19(7.1 \%)$ & $2(4.3 \%)$ & $4(6.9 \%)$ & $13(7.9 \%)$ & $0.69^{3}$ \\
\hline APD, no. of cases (\%) & $\begin{array}{l}36 \\
(13.4 \%)\end{array}$ & $9(19.1 \%)$ & $8(13.8 \%)$ & $19(11.6 \%)$ & $0.40^{3}$ \\
\hline \multicolumn{6}{|l|}{ Dialysis adequacy } \\
\hline Weekly total Kt/V & $\begin{array}{l}2.00 \pm \\
0.79\end{array}$ & $\begin{array}{l}2.24 \pm \\
0.56\end{array}$ & $\begin{array}{l}2.07 \pm \\
0.84\end{array}$ & $1.92 \pm 0.82$ & $0.09^{3}$ \\
\hline Residual GFR $\left(\mathrm{ml} / \mathrm{min} / 1.73 \mathrm{~m}^{2}\right)$ & $\begin{array}{l}3.53 \pm \\
2.90\end{array}$ & $\begin{array}{l}3.63 \pm \\
2.75\end{array}$ & $\begin{array}{l}3.08 \pm \\
2.94\end{array}$ & $3.66 \pm 2.93$ & $0.52^{3}$ \\
\hline Residual urine volume (L) & $\begin{array}{l}0.97 \pm \\
0.79\end{array}$ & $\begin{array}{l}0.97 \pm \\
0.81\end{array}$ & $\begin{array}{l}0.88 \pm \\
0.85\end{array}$ & $1.0 \pm 0.77$ & $0.74^{3}$ \\
\hline NPNA (g/kg/day) & $\begin{array}{l}1.07 \pm \\
0.38\end{array}$ & $\begin{array}{l}1.18 \pm \\
0.28\end{array}$ & $\begin{array}{l}1.06 \pm \\
0.37\end{array}$ & $1.04 \pm 0.40$ & $0.18^{3}$ \\
\hline
\end{tabular}

Continuous variables were expressed as mean \pm standard deviation or median (interquartile range) for normally distributed and non-normally distributed variables respectively.

Abbreviations: APD, automated peritoneal dialysis, APD; D/P, dialysate-to-plasma concentration ratio; GFR, glomerular filtration rate; NPNA, normalized protein nitrogen appearance; $\mathrm{OH} / \mathrm{ECW}$ : ratio of overhydration to extracellular water; PD, peritoneal dialysis. 
${ }^{1}$ Data were compared by Chi-square test

${ }^{2}$ Data were compared by Kruskal-Wallis test

${ }^{3}$ Data were compared by one-way ANOVA

${ }^{\text {a }}$ Moderate to severe fluid overload vs mild fluid overload, $\mathrm{P}<0.01$

${ }^{b}$ Moderate to Severe fluid overload vs. normohydration, $\mathrm{P}<0.01$

${ }^{c}$ Moderate to Severe fluid overload vs. normohydration, $\mathrm{P}<0.05$

${ }^{\mathrm{d}}$ Mild fluid overload vs. normohydration, $\mathrm{P}<0.05$

e Mild fluid overload vs. normohydration, $\mathrm{P}<0.01$

TABLE 2. Moderators of volume status (relative hydration index) by multivariate mixed linear model

\begin{tabular}{|lll|}
\hline Covariates & $\begin{array}{l}\text { Estimated changes (95\% confidence } \\
\text { interval) }\end{array}$ & P-value \\
\hline Age (per 10 year) & $-0.9 \%(-1.7 \%$ to $-1.2 \%)$ & 0.02 \\
\hline Male sex & $1.8 \%(-0.2 \%$ to $3.9 \%)$ & 0.08 \\
\hline Diabetes (versus no diabetes) & $7.3 \%(5.5 \%$ to $9.1 \%)$ & $<0.0001$ \\
\hline Systolic blood pressure (per 10mm Hg) & $0.8 \%(0.5 \%$ to $1.1 \%)$ & $<0.0001$ \\
\hline Albumin (per 10g/L) & $-3.5 \%(-5.0 \%$ to $-2.1 \%)$ & $<0.0001$ \\
\hline Hemoglobin (per 1g/dL) & $-0.7 \%(-1.2 \%$ to $-0.2 \%)$ & 0.004 \\
\hline Weekly Kt/V (per 0.1 unit) & $-0.2 \%(-0.4 \%$ to $-0.1 \%)$ & 0.006 \\
\hline Residual urine volume (per 100ml) & $-0.05 \%(-0.2 \%$ to $0.1 \%)$ & 0.45 \\
\hline $\begin{array}{l}\text { D/P creatinine (at } 4 \text { hour) at baseline (per } 0.1 \\
\text { unit) }\end{array}$ & $0.04 \%(-0.6 \%$ to $0.5 \%)$ & 0.89 \\
\hline $\begin{array}{l}\text { Lean tissue index (per kg/m2) } \\
\text { Fat tissue index (per kg/m2) }\end{array}$ & $-0.9 \%(-1.2 \%$ to $-0.5 \%)$ & $<0.0001$ \\
\hline $\begin{array}{l}\text { Normalized protein nitrogen appearance (per } \\
\text { g/kg/day) }\end{array}$ & $-0.5 \%(-0.8 \%$ to $-0.3 \%)$ & $<0.0001$ \\
\hline
\end{tabular}


TABLE 3. Change of volume status over time in different subgroups

\begin{tabular}{|c|c|c|c|c|c|}
\hline & $\begin{array}{l}\text { Baseline } \\
\text { RHI (\%) }\end{array}$ & $\begin{array}{l}\text { Adjusted } \\
\text { difference in } \\
\text { RHI between } \\
\text { groups at Year } \\
0\end{array}$ & $\begin{array}{l}\text { Adjusted } \\
\text { difference in } \\
\text { RHI between } \\
\text { groups at Year } \\
1\end{array}$ & $\begin{array}{l}\text { Mean } \\
\text { annual } \\
\text { change in } \\
\text { RHI (\% per } \\
\text { year) }\end{array}$ & $\begin{array}{l}\text { Adjusted mean } \\
\text { difference in annual } \\
\text { change in RHI between } \\
\text { groups (\% per year) }\end{array}$ \\
\hline \multicolumn{6}{|l|}{$\begin{array}{l}\text { Baseline } \\
\text { volume } \\
\text { status }\end{array}$} \\
\hline $\mathrm{RHI}>7 \%$ & $\begin{array}{l}20.8 \\
(19.5 \text { to } \\
22.1)\end{array}$ & 0 (reference) & 0 (reference) & $\begin{array}{l}-0.6(-1.4 \text { to } \\
0.3)\end{array}$ & 0 (reference) \\
\hline $\mathrm{RHI} \leq 7 \%$ & $\begin{array}{l}6.3(3.4 \\
\text { to } 9.2)\end{array}$ & $\begin{array}{l}-14.5(-17.7 \text { to } \\
-11.3)^{a}\end{array}$ & $\begin{array}{l}-6.1(-9.2 \text { to } \\
-3.0)^{a}\end{array}$ & $\begin{array}{l}2.6(1.1 \text { to } \\
4.2)\end{array}$ & $3.2(1.5 \text { to } 4.9)^{a}$ \\
\hline \multicolumn{6}{|l|}{$\begin{array}{l}\text { Baseline } \\
\text { residual } \\
\text { urine } \\
\text { output }\end{array}$} \\
\hline $200 \mathrm{ml} /$ day & $\begin{array}{l}18.8 \\
(17.3 \text { to } \\
20.4)\end{array}$ & 0 (reference) & 0 (reference) & $\begin{array}{l}-0.3(-1.3 \text { to } \\
0.7)\end{array}$ & 0 (reference) \\
\hline $\begin{array}{l}<00 \mathrm{ml} / \text { day } \\
20\end{array}$ & $\begin{array}{l}16.3 \\
(12.7 \text { to } \\
19.8)\end{array}$ & $\begin{array}{l}2.6(-1.4 \text { to } \\
6.6)\end{array}$ & $\begin{array}{l}-3.7(-7.7 \text { to } \\
0.4)^{b}\end{array}$ & $\begin{array}{l}1.1(-1.0 \text { to } \\
3.1)^{(1)}\end{array}$ & $1.4(-0.9$ to 3.7$)$ \\
\hline
\end{tabular}

Abbreviations: $\mathrm{RHI}$, relative hydration index

Data are presented as mean ( $95 \%$ confidence interval)

The model was adjusted for age, gender, diabetes, baseline transporter status, $\mathrm{Kt} / \mathrm{V}$, residual urine output, systolic blood pressure, serum albumin, hemoglobin, lean tissue index, fat tissue index and normalized protein nitrogen appearance. ${ }^{\mathrm{a}} \mathrm{P}<0.01 ; \mathrm{b} P=0.07$

TABLE 4. Prognostic value of baseline volume status, variability of volume status and time-averaged volume status in different models considering patient survival and technique survival 


\begin{tabular}{|c|c|c|c|c|c|c|c|c|c|}
\hline & \multicolumn{3}{|c|}{ Model $1^{1}$} & \multicolumn{3}{|c|}{ Model $2^{2}$} & \multicolumn{3}{|c|}{ Model $3^{3}$} \\
\hline & SHR & $95 \% \mathrm{Cl}$ & $\begin{array}{l}\mathrm{P}- \\
\text { value }\end{array}$ & SHR & $\begin{array}{l}95 \% \\
\mathrm{Cl}\end{array}$ & P-value & SHR & $\begin{array}{l}95 \% \\
\mathrm{Cl}\end{array}$ & P-value \\
\hline \multicolumn{10}{|l|}{ Patient survival } \\
\hline $\begin{array}{l}\text { Baseline RHI (per } \\
\text { 1\%) }\end{array}$ & 1.03 & $\begin{array}{l}1.004- \\
1.053\end{array}$ & 0.02 & - & - & - & & & \\
\hline $\begin{array}{l}\text { Time-averaged } \\
\text { RHI (per 1\%) }\end{array}$ & - & - & - & 1.05 & $\begin{array}{l}1.03- \\
1.08\end{array}$ & $<0.0001$ & 1.05 & $\begin{array}{l}1.03- \\
1.08\end{array}$ & $<0.0001$ \\
\hline VVS (per 1 unit) & - & - & - & - & - & - & 0.96 & $\begin{array}{l}0.79- \\
1.16\end{array}$ & 0.65 \\
\hline Model $\chi^{2}$ & 48.7 & & & $86.1^{a}$ & & & $85.7^{b}$ & & \\
\hline \multicolumn{10}{|l|}{$\begin{array}{l}\text { Technique } \\
\text { survival }\end{array}$} \\
\hline $\begin{array}{l}\text { Baseline RHI (per } \\
1 \% \text { ) }\end{array}$ & 1.03 & $\begin{array}{l}1.002- \\
1.048\end{array}$ & 0.03 & - & - & - & & & \\
\hline $\begin{array}{l}\text { Time-averaged } \\
\text { RHI (per 1\%) }\end{array}$ & - & - & - & 1.04 & $\begin{array}{l}1.01- \\
1.06\end{array}$ & 0.001 & 1.04 & $\begin{array}{l}1.02- \\
1.06\end{array}$ & 0.001 \\
\hline VVS (per 1 unit) & - & - & - & - & - & - & 0.99 & $\begin{array}{l}0.83- \\
1.19\end{array}$ & 0.93 \\
\hline Model $\chi^{2}$ & 50.0 & & & $66.0^{c}$ & & & $65.9^{d}$ & & \\
\hline
\end{tabular}

${ }^{1}$ Model 1 was adjusted for age, gender, baseline Charlson Comorbidity Index, baseline body mass index, baseline serum albumin, $\mathrm{Kt} / \mathrm{V}$ and residual urine output

${ }^{2}$ Model 2 was adjusted for age, gender, baseline Charlson Comorbidity Index, time-averaged body mass index, time-averaged serum albumin, $\mathrm{Kt} / \mathrm{V}$ and residual urine output

${ }^{3}$ Model 3 was adjusted for same variables of model $2+$ VVS

a Patient survival: Model 2 vs. model $1(P=0.0001)$

${ }^{b}$ Patient survival: Model 3 vs. model $2(P=0.6)$

${ }^{c}$ Technique survival: Model 2 vs. model $1(P=0.002)$

d Technique survival: Model 3 vs. Model $2(P=0.56)$ 
Abbreviations: RHI, relative hydration index; SHR: subdistribution hazard ratio; VVS, variability in volume status

\section{Figures}

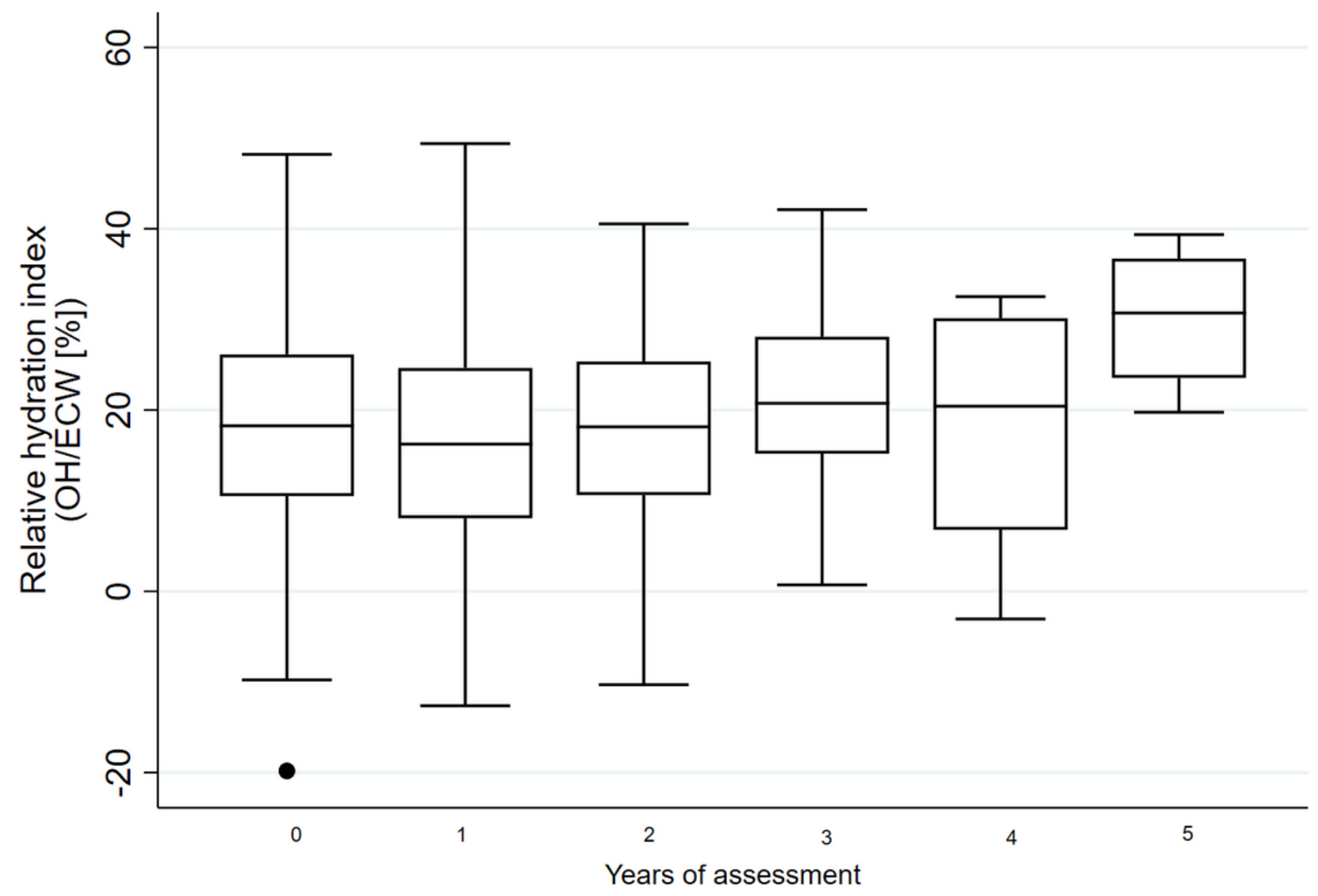

Figure 1

Change in relative hydration index $(\mathrm{RHI})$ of the whole cohort over time. The upper border, central line, and lower border of the boxplot depicted 75th percentile, median and 25th percentile, respectively. The whiskers indicated 1.5 times of interquartile range from 25 th or 75 th percentile. 

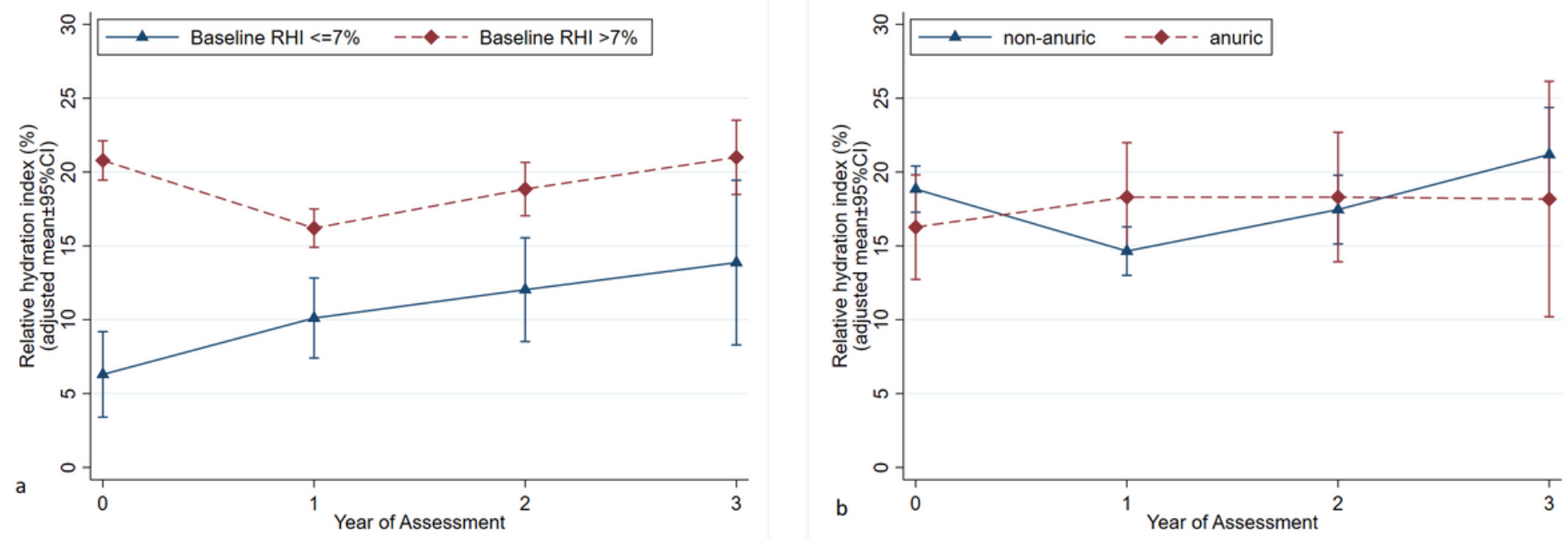

\section{Figure 2}

Change in relative hydration index $(\mathrm{RHI})$ in the first 3 years, when patients were grouped according to $(\mathrm{A})$ baseline volume status ( $\mathrm{RHI} \leq 7 \% \mathrm{vs}$. $>7 \%$ ); (B) baseline residual urine output ( $<200 \mathrm{ml}$ vs. $\geq 200 \mathrm{ml}$ ). The error bar indicated standard error.
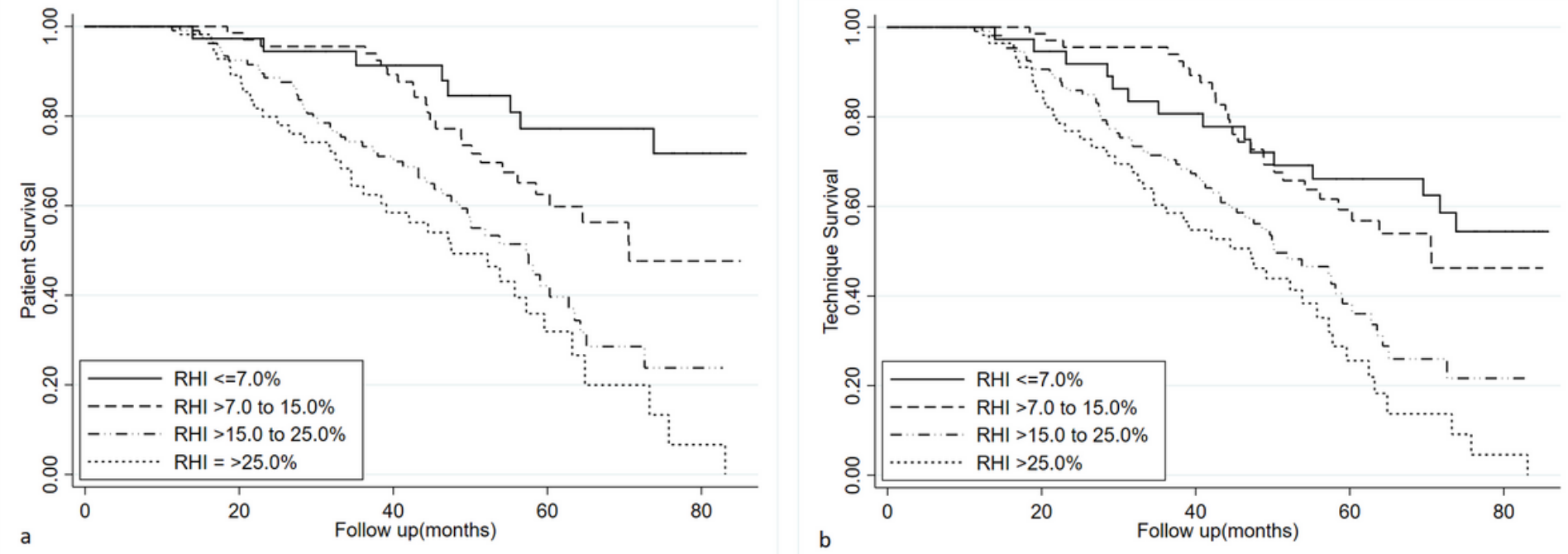

Figure 3

Kaplan-Meier plot of (A) patient survival; and (B) technique survival. Patients were grouped according to degree of fluid overload (FO) (nil: $\mathrm{RHI} \leq 7 \%$, mild: $>7-15 \%$; moderate: $>15-25 \%$; severe FO: $>25 \%$; log-rank test, $\mathrm{P}<0.0001$ for both comparisons).

\section{Supplementary Files}

This is a list of supplementary files associated with this preprint. Click to download.

- STROBEchecklistcohort.docx 
- TABLES1S3JNep.docx 